\title{
Correction to: Re-Examining the Effect of Maternal Employment on Child Overweight: The Case of School-Age Children
}

\author{
Bezawit T. Agiro ${ }^{1}$ (1) $\cdot$ Wei-Chiao Huang ${ }^{2,3}$
}

Published online: 6 May 2020

○) Springer Science+Business Media, LLC, part of Springer Nature 2020

\section{Correction to: \\ Journal of Family and Economic Issues (2020) 41:140-157 \\ https://doi.org/10.1007/s10834-019-09658-8}

The original publication of the article does not indicate the additional affiliation of the co-author Wei-Chiao Huang. The additional affiliation should read as follows "Specially Appointed Professor, City College, Wuhan University of Science and Technology". Secondly, the error in the corresponding author information has subsequently been identified in the original publication. It should read as follows “Bezawit T. Agiro, bezawit.agiro@nebraska.gov.

The original article can be found online at https://doi.org/10.1007/ s10834-019-09658-8.

Bezawit T. Agiro

bezawit.agiro@nebraska.gov

1 Department of Revenue, State of Nebraska, 301 Centennial Mall South, Lincoln, NE 68509, USA

2 Department of Economics, Western Michigan University, 1903 Western Michigan Avenue, Kalamazoo, MI 49008, USA

3 City College, Wuhan University of Science and Technology, Wuhan, China
Publisher's Note Springer Nature remains neutral with regard to jurisdictional claims in published maps and institutional affiliations. 